\title{
Why can't we be friends? Entitlements and the costs of conflict
}

\author{
Erik O Kimbrough \\ Department of Economics, Simon Fraser University
}

\author{
Roman M Sheremeta \\ Weatherhead School of Management, Case Western Reserve University \& \\ Economic Science Institute, Chapman University
}

Forthcoming in the Journal of Peace Research, 2014

\begin{abstract}
We design an experiment to explore the impact of earned entitlements on the frequency and intensity of conflicts in a two-stage conflict game where players may attempt to use nonbinding side-payments to avoid conflict. In this game, Proposers make offers and Responders decide simultaneously whether to accept the offers and whether to engage in a conflict. A simple theoretical analysis suggests that Proposers should never offer side-payments because Responders should always accept them and then still choose to enter conflict; however, our experiment reveals that some individuals use this non-binding mechanism to avoid conflict. Moreover, when subjects earn their roles (Proposer or Responder), conflicts are $44 \%$ more likely to be avoided than when roles are assigned randomly. Earned entitlements impact behavior in three important ways: (1) Proposers who have earned their position persistently make larger offers; (2) larger offers lead to a lower probability of conflict, but (3) Proposers whose offers do not lead to conflict resolution respond spitefully with greater conflict expenditure. Hence, with earned rights, the positive welfare effects of reduced conflict frequency are offset by higher conflict intensity. This result differs from previous experimental evidence from ultimatum games in which earned entitlements tend to encourage agreement and increase welfare; thus, our findings highlight the important consequences of endogenizing the costs of conflict. Our analysis suggests that earned entitlements alter behavior by influencing the beliefs of Proposers about the willingness of Responders to accept a peaceful resolution. As a result, these Proposers make persistent high offers, and when their beliefs are disappointed by a Responder's decision to accept a side-payment and still enter conflict, they retaliate.
\end{abstract}

JEL Classifications: C72, C91, D72

Keywords: contests, conflict resolution, side-payments, entitlements, experiments

Corresponding author: $\underline{\text { rms246@ case.edu, sheremet@ chapman.edu }}$ 


\section{Introduction}

When you reap the harvest of your land, do not reap to the very edges of your field or gather the gleanings of your harvest. Do not go over your vineyard a second time or pick up the grapes that have fallen. Leave them for the poor and the alien. (Leviticus 19:9-10)

The God of the Old Testament instructed his followers to leave some of the fruits of their harvest in their fields, un-harvested. An economist might assume merely that God understood the Law of Diminishing Returns and taught his followers accordingly. But to ignore the exhortation to leave something behind for the poor and alien is to miss a potentially rich historical and economic point. Why, beyond the diminishing returns to labor, might one want to leave unpicked fruit on a vine?

The property rights to the goods are clearly delineated in this story. No indication is given that the people for whom the gleanings are to be left have any claim to the harvest through the application of their labor or capital to the production process. Furthermore, that one indirect object of the exhortation is "the alien" (that is, foreigners and persons unknown) rules out the folk theorem and the shadow of the future as explanations. One way to reconcile these issues, then, is to postulate altruistic intentions or social preferences. However, this explanation ignores a few historical facts which, taken together, suggest an altogether different interpretation.

During the historical era in which this text was written, the world of the Jewish people was in upheaval. Ravaged by war, famine, and forced migrations in the previous century, the people had begun to resettle, but for each family that settled a piece of land, there was another traveling in search of a place of its own. ${ }^{1}$ The poor wanderer who hungrily stumbled upon a thriving farm would have been tempted to steal from the farm for sustenance. Violence to one's property likely would have been met with violence, and costly conflict ensued. In this context, the idea of leaving unpicked fruit for "the poor and alien" begins to look more strategic and less

\footnotetext{
${ }^{1}$ Whether one accepts the timeline laid out in the text of the Old Testament itself (Genesis 12:4-9, 26:12-22; Exodus 14:5-9; Joshua 13:1-32) or one follows the standard view of Biblical historians who argue that Leviticus was first put to paper in the wake of the Babylonian Captivity c. 500 BCE (Warington, 1873; Harris, 1985), this narrative can be demonstrated to reflect the experience of the Jewish people.
} 
altruistic. The leftover goods take on the characteristics of a side-payment, offered by the farmer to ward off predation. ${ }^{2}$

In societies without strong institutional structures, the prospect of resource conflict is similarly ubiquitous. To reduce the risk of conflict, groups often uphold informal norms of reciprocal gift-giving, tolerated theft, and sharing (see e.g., Gurven, 2004; Henrich et al., 2005; Schechter, 2007). However, any (implicit or explicit) promises to avoid conflict made in the context of an informal norm are unenforceable. Thus, when one party offers resources to another in order to deter predation, there is always the risk that the payment is accepted and then conflict occurs anyway. A similar dynamic is at play in international politics. For example, aid may be offered to some nations under the condition that the leaders from aid-receiving nations adopt certain policies, but since such promises are unenforceable, a nation may accept aid and nevertheless fail to change policy (Kanbur, 2006; Temple, 2010). In the context of the Cold War, many aid payments were explicitly made with the goal of avoiding conflict - aid was offered to prevent nations from joining "the other side". Such aid was clearly not always effective.

Because of the incentive problems discussed above, most models of conflict resolution rely on the ability of parties to commit to a plan of action. For example, if contracts are enforceable, then binding, strategy-contingent transfer payments are sufficient to obviate costly conflicts in both theory and practice (Anbarci et al., 2002; Muthoo, 2004; Garfinkel \& Skaperdas, 2007; Esteban \& Sakovics, 2008; Kimbrough \& Sheremeta, 2013). ${ }^{3}$ Nevertheless, in many conflicts, parties often incur large costs despite the possibility of Pareto improving resolutions. Experimental evidence suggests that individuals are prone to reject Pareto improving settlements when the proposed outcome is perceived as unfavorable (or unfair) ${ }^{4}$ and some individuals may simply enjoy fighting (or winning) ${ }^{5}$. On the other hand, there is some evidence that even in the absence of enforceable contracts, individuals can achieve Pareto improvements by employing conventions, reputation-based mechanisms, reciprocity, and cheap talk, particularly in the context of the informal norms mentioned above. ${ }^{6}$ However, it is unclear under

\footnotetext{
2 Jones (1994) offers a similar argument for the emergence of human food sharing in general.

${ }^{3}$ For a comprehensive review of the theoretical literature see Garfinkel and Skaperdas (2012) and for the experimental literature see Dechenaux et al. (2012).

${ }^{4}$ See Hoffman \& Spitzer (1985), Guth \& Tietz (1990) and Henrich et al. (2001) for experimental evidence.

${ }^{5}$ Sheremeta (2010a, 2010b) find that subjects expend resources seeking a prize worth nothing.

${ }^{6}$ Maynard Smith \& Parker (1976) and Maynard Smith (1982) first demonstrated that employing conventions is an evolutionarily stable strategy in Hawk-Dove games. Similar conventions can emerge to solve numerous other coordination problems (Young, 1993; Sugden, 2005). Hafer (2006) shows that in a repeated conflict over a resource
} 
what circumstances non-binding mechanisms can be employed to avert conflict. Our research is designed to help resolve this question in a controlled laboratory setting that captures many of the important features of conflicts outside the lab while facilitating causal inference. In that light, we view laboratory studies as an important complement to field studies (Imai et al., 2011).

Our experiment is built on a two-stage conflict game with side-payment offers (Kimbrough \& Sheremeta, 2013). In this game, Proposers make offers and Responders decide whether to accept the offers and whether to engage in a conflict over a valuable resource. Specifically, the game consists of two stages. In the bargaining stage, the Proposer offers a sidepayment to the Responder in an attempt to keep the resource and to avoid participation in a lottery contest in the conflict stage. After receiving the offer from the Proposer, the Responder decides whether to accept the offer and also whether to enter the conflict. Hence, the Responder may accept the offer and nevertheless enter the conflict. If the Responder accepts the offer, the Responder's payoff increases by the amount of the offer and the Proposer's payoff decreases by the same amount. However, if the Responder rejects the offer (or accepts the offer and still enters the conflict), both players advance to the conflict stage, in which they compete for the resource in a lottery contest. Since the side-payment contract is not enforceable, the subgame perfect Nash equilibrium is for the Proposer to make a zero side-payment offer and for the Responder to accept any offer and enter the conflict anyway.

Previous experimental evidence from Kimbrough \& Sheremeta (2013) indicates that some Proposers make large offers and some Responders accept those offers and choose not to enter conflict, even in anonymous, one-shot interactions. This suggests a potentially valuable role for non-binding conflict resolution mechanisms; and our paper is motivated by the observation that the likelihood of conflict resolution may be even higher if entitlements (or property rights) to the resource are clearly assigned ex ante. Thus, we employ two treatments to explore the impact of earned entitlements on the frequency and intensity of conflicts in the simple conflict game described above. In the Random treatment, we model a situation in which one party has come to possess a valuable resource by chance, and in the Earned treatment, we

with incomplete information, possession is a signal of success in previous conflicts and can establish expectations among potential contestants that support equilibria in which no conflict occurs. Muthoo (2004) shows how transfers can reduce conflict in repeated games of production and appropriation. Tingley \& Walter (2011) show how cheap talk deterrence efforts impact conflict rates in an entry game. 
model a situation closer to that described in the biblical passage above in which one party has earned the resource.

It is well documented in experimental literature that property rights (entitlements) significantly affect behavior in ultimatum, dictator, and team production bargaining games (Hoffman et al., 1994, 1998; Cherry et al., 2002; Oxoby \& Spraggon, 2008; Gachter \& Riedl, 2005), and there is also anthropological evidence that people treat windfall gains differently than hard-earned gains; see e.g., Henrich et al. (2005) and associated commentary. In general, inducing a property right leads to more self-regarding behavior on the behalf of the right-holder and more acceptance of such behavior by others without rights. To see how a perceived property right could impact bargaining in a two-stage conflict game, suppose that a contested resource is first discovered by one individual, call him the resident (i.e., the Proposer), and only later contested by another, the contestant (i.e., the Responder). If the contestant believes that the resident has a property right to the resource, then she may be more likely to accept a contractual resolution, and knowing this, the resident may be more willing to offer a side-payment. ${ }^{7}$ This is the effect that has been observed in previous work on entitlements in bargaining games, but our design introduces a second dimension on which property rights may have an impact. Specifically, previous experiments have employed exogenous disagreement payoffs, but in the conflict game, rent dissipation is endogenous, and thus the impact of earned entitlements may also be observed in conflict expenditures. For example, if first possession creates an endowment effect in the resident, say, by reference to some social convention (finders keepers), then all else equal, the resident may be willing to fight harder than the contestant for the resource. ${ }^{8}$

While the examples that we considered so far emphasize the impact of entitlements on interpersonal conflict, it should be clear that the underlying ideas are applicable to any level of organization. For example, Butler \& Gates (2012) model conflict over rangeland in Africa and show how asymmetric entitlements can actually lead to conflict if one side is persistently disadvantaged. ${ }^{9}$ More generally, territorial disputes between nations have many of the same

\footnotetext{
${ }^{7}$ Empirical studies of animal territoriality frequently identify a 'residency effect'; that is, first possessors disproportionately win resource contests (Haley, 1994; Alcock \& Bailey, 1997; Kemp \& Wiklund, 2004), and a recent experiment by DeScioli and Wilson (2011) documents the residency effect in human subjects.

${ }^{8}$ Gintis (2007) exploits the logic of Parker's (1974) "fighting assessment" to show how such a tendency could describe the origin of property rights in wars of attrition: if the contestant knows that the resident will be willing to expend more effort on defense than she will on offense, then she should respond by choosing not to fight.

${ }^{9}$ The intuition is similar to that in Grafen (1987), who shows that when one side is persistently in disadvantageous position, "desperado" behavior may be optimal.
} 
features as those between individuals and smaller groups, and perceptions about who is entitled to a particular area may shape the nature and likelihood of conflict. The results of our experiment show that this is exactly the case.

We find that when subjects earn their rights to be either Proposer or Responder, conflicts are $44 \%$ more likely to be avoided than when roles are assigned randomly. Earned rights impact behavior in three important ways: (1) Proposers who have earned their position persistently make larger offers; (2) larger offers lead to a lower probability of conflict, but (3) Proposers whose offers do not lead to conflict resolution respond spitefully and exhibit greater conflict expenditure. Hence, with earned rights, the positive welfare effects of reduced conflict frequency are offset by higher conflict intensity.

Our findings are of interest both to field researchers and to those studying conflict and conflict resolution inside the lab. Outside the lab, conflicting perceptions of entitlement are often essential components of conflict (Gurven, 2004; Schechter, 2007), and our experiment provides clear casual evidence on how entitlements (earned versus randomly assigned) impact bargaining and conflict. Our finding that the conflict avoidance benefits of earned rights are offset by increased conflict intensity is of particular interest to researchers studying conflict and conflict resolution in the laboratory (Linster et al., 2001; Arce et al., 2011; Tingley, 2011; Deck \& Sheremeta, 2012; Dechenaux et al., 2012). Most previous studies of earned rights indicate that they are successful at reducing the costs of conflict - e.g. in ultimatum games, increased acceptance of offers is equivalent to reduced waste. Our results suggest that the impact of earned rights may not be so sanguine, as conditional on conflict occurring, earned rights increase its intensity. Our design allowed us to identify this effect by endogenizing the costs of conflict. In the discussion, we argue that the impact of earned rights operates largely by changing the beliefs of participants, and suggest directions for future research.

\section{Experimental environment, design, predictions and procedures}

\section{Experimental environment and model predictions}

Our experiment examines a two-player conflict game in which both players expend resources competing for an indivisible resource that each value at $v=60$. The game is divided into two sequential stages: the bargaining stage and the conflict stage. In the bargaining stage, the Proposer offers a side-payment $s$ between 0 and 60 to the Responder in an attempt to avoid 
participation in a rent-seeking lottery contest in the conflict stage. After receiving the sidepayment offer $s$ from the Proposer, the Responder decides whether to accept the offer and also whether to enter the conflict. Hence, the Responder may accept a side-payment $s$ and nevertheless enter the conflict. If the Responder accepts the offer and decides not to enter the conflict, the game ends with the Responder receiving a payoff of $s$ and the Proposer receiving a payoff of $v-s$, and neither player enter the conflict stage. In such a case, the surplus split between the two players is $\Pi=s+v-s=v=60$. However, if the Responder rejects the offer (or accepts the offer and still enters the conflict), both players advance to the conflict stage, in which, according to our instructions, the Responder "may attempt to take" the prize from the Proposer.

In the conflict stage, the Proposer and the Responder partake in the rent-seeking lottery contest due to Tullock (1980) between two symmetric players (i.e., player 1 and player 2). Both players expend costly resources $e_{1}$ and $e_{2}$ to increase their probabilities of winning the prize. A player $i^{\text {'s }}$ probability of winning is defined by a lottery contest success function, i.e., $p_{i}\left(e_{1}, e_{2}\right)=$ $e_{i} /\left(e_{1}+e_{2}\right)$. The expected payoff for a risk-neutral player $i$ is $E\left(\pi_{i}\right)=p_{i}\left(e_{1}, e_{2}\right) v-e_{i}$. By differentiating $E\left(\pi_{i}\right)$ with respect to $e_{i}$ and solving the best response functions simultaneously, we obtain unique Nash equilibrium expenditure levels $e_{1}{ }^{*}=e_{2}{ }^{*}=v / 4=15$. Given the equilibrium expenditures, the expected payoffs of both players are $E\left(\pi_{1}{ }^{*}\right)=E\left(\pi_{2}{ }^{*}\right)=v / 4=15$. Hence, the equilibrium prediction for the Tullock contest, independent of the bargaining stage, is that both players will expend 15 and each will receive on average a payoff of 15 . Given that the game proceeds to the conflict stage, the equilibrium surplus split between the two players is $\Pi^{*}=$ $E\left(\pi_{1}^{*}\right)+E\left(\pi_{2}^{*}\right)=v / 2=30$.

Going back to the bargaining stage, since the side-payment offer is non-binding, the Responder has a dominant strategy to always accept the side-payment $s$ and to enter the conflict stage, where she earns an additional expected payoff of 15 (this is because the prize is indivisible and $s$ is withdrawn from the Proposer's initial endowment). Thus, knowing that the Responder cannot be dissuaded from conflict in the bargaining stage, the Proposer should never offer a sidepayment, i.e., $s^{*}=0$, and the game should always reach the conflict stage. Hence, the subgame perfect Nash equilibrium is for the Proposer to offer a side-payment of zero and for the Responder to accept all the offers and always enter the conflict. 


\section{Experimental design}

Building on this environment, we employ a between-subjects experimental design to explore the impact of earned rights on the frequency and intensity of conflict. Our treatments vary whether a subject's assignment to the role of Proposer is Earned or Random. In the Earned treatment, after reading the instructions, all subjects took a ten-question, general knowledge quiz. Subjects were ranked by the number of questions they answered correctly and ties were broken by how quickly the answers were submitted. The subjects knew that they would be assigned their roles on the basis of their performance on the quiz. They were also told that the top performers on the quiz had "earned the right to be Proposers" and that the bottom half were assigned to be Responders. While the instructions in all treatments indicated that Proposers had prior claims to the resource - recall the statement that Responders "may attempt to take" the resource from Proposers - in the Earned treatment we allocate these prior claims by relative performance on the quiz rather than randomly, as in the other treatments. The outline of the experimental design and theoretical predictions are shown in Table 1.

\section{The hypothesized effects of earned rights}

Note that the Earned treatment changes neither the structure of the game nor the expected payoffs relative to the Random treatment, so the theoretical predictions under the standard money-maximizing model do not change. Nevertheless, it has been well documented in experimental literature that when subjects earn their roles, their behavior changes (Hoffman et al., 1994, 1998; Cherry et al., 2002; Oxoby \& Spraggon, 2008; Gachter \& Riedl, 2005). Based on previous findings, we suggest several hypotheses as to the impact of earned rights on the frequency and intensity of conflicts.

In general, we argue that when subjects earn their roles and the initial allocation of resources clearly assigns first-mover rights to one individual, cooperation will be easier because subjects' expectations will be aligned. Specifically, we expect that earned rights will decrease conflict entry by Responders because Responders will be more inclined to respect the rights of Proposers who make positive offers (Gachter \& Riedl, 2005).

Hypothesis 1: Earned rights decrease the rate of conflict entry by Responders, controlling for the amount offered. 
The first hypothesis suggests that ceteris paribus, earned rights should decrease the frequency of conflicts and increase the probability of conflict resolution. We emphasize that this result should be stated conditionally on the offer amount, since as we discuss below, there are $e x$ ante plausible arguments that earned rights will move offers in either direction. Nevertheless, to the extent that Responders' respect the earned rights of Proposers, then an identical offer should be more likely to be accepted in the Earned than in the Random treatment. At the same time, earned rights may also lead to heavier fighting by Proposers because rebuffed attempts at cooperation can lead to retaliation. This can also be interpreted as earned rights producing an endowment effect (Gintis, 2007).

Hypothesis 2: Conditional on conflict, earned rights increase conflict expenditures by Proposers.

Thus, we hypothesize that earned rights will decrease the frequency of conflicts, conditional on offer amounts, and increase the probability of conflict resolution (Hypothesis 1). However, if and when conflict ensues, we expect Proposers to react spitefully because they will believe that their property right is being disrespected (Hypothesis 2).

Finally, the expected effect of earned rights on offers is indeterminate because there are two potential effects. First, those subjects who would already seek to cooperate by making positive offers when rights are randomly assigned may decrease their offers if they believe they have earned the right to a larger share of the surplus (Hoffman et al., 1994). On the other hand, some Proposers who would not make positive offers if rights were randomly assigned may now choose to offer positive amounts because they believe that a sufficient offer will induce nonentry, and this may increase offers on average. ${ }^{10}$ Since both of these interpretations are intuitively plausible and we have no ex ante criteria for distinguishing them, we do not state a formal hypothesis about the impact of earned rights on offers. We simply note that behavior would in either case be jointly determined by the influence of earned rights on the beliefs of participants. We return to this idea later when we discuss the prospects for future research on this topic.

\footnotetext{
${ }^{10}$ Since we employ a between-subjects design, we do not observe the impact of earned rights within-subject.
} 


\section{Procedures}

To test these hypotheses we ran three experimental sessions of each treatment with 12 subjects per session. Each session consisted of 30 periods of a single treatment in which subjects were randomly and anonymously re-matched in each period. Subjects were assigned the role of either Proposer or Responder (randomly in the Random treatment and earned through quiz competition in the Earned treatment), and they persisted in that role throughout. At the end of each experimental session, subjects completed a brief demographic survey. To reinforce the oneshot incentives of the game, subjects knew beforehand that we would select five of the 30 periods for payment using a bingo cage; subjects' earnings from these five periods were added to or subtracted from a participation fee of $\$ 20$. We converted endowments and earnings to USD at a rate of $30=\$ 1$ and subjects were paid privately in cash at the end of the experiment. Sessions lasted one hour each.

Subjects were recruited at random from the undergraduate student body of Chapman University. Subjects sat at, and interacted via, visually isolated computer terminals, and instructions were read aloud by the experimenter as subjects followed along on paper. Subjects received their earnings in cash privately at the end of each session. The average experimental earnings, including the $\$ 20$ participation fee, were $\$ 22.6$, ranging from a low of $\$ 16.0$ to a high of \$28.3. No subject participated more than once, and no subject had prior experience with a similar experimental environment. Instructions for the Earned treatment are included in the Appendix. Instructions for the other treatments and the quiz are available from the authors upon request.

\section{Results}

\section{Comparisons to the theory}

Table 2 displays summary statistics for our treatments. Theory predicts a total surplus of 30 in both the Random and Earned treatments (see Table 1). However, the data from the experiment indicate that in the Random and Earned treatments, the average surpluses of 20.3 and 18.4 are significantly lower than the theoretical prediction of 30.

Finding 1: Surplus in both treatments is smaller than predicted. 
To support these conclusions we estimated simple panel regressions separately for each treatment, where the dependent variable is the surplus (payoff) and the independent variables are a constant and a period trend. The models included a random effects error structure, with the individual subject as the random effect, to account for the multiple decisions made by individual subjects. The standard errors were clustered at the session level, to control for the fact that multiple subjects repeatedly interacted with each other in a given session. Based on Wald tests conducted on estimates of each model, we found that surplus in all treatments is significantly lower than predicted $(p<0.01)$.

Furthermore, much of the predicted surplus is lost due to substantial overinvestment in conflict relative to the predictions (see Figures 1a and 1b). Additional panel regressions for each treatment where conflict expenditure is the dependent variable and the independent variables are a constant, a dummy variable indicating whether the subject was a Responder, and a period trend indicate that these differences are statistically significant. As before, we include a random effects error structure by subject to account for multiple observations, and we cluster standard errors by session. Wald tests confirm that expenditures are greater than the predicted value of 15 ( $p<$ 0.01), and the coefficient on the Responder dummy is positive but insignificant for all treatments.

However, the welfare losses due to over-dissipation are actually understated by the fact that some pairs in both the Random and Earned treatments are able to use side-payment offers to avoid conflict - with probabilities 0.16 and 0.23 , respectively. Figures $2 \mathrm{a}$ and $2 \mathrm{~b}$ display histograms of side-payment offers for each treatment, and we confirm that offers are also significantly larger than predicted by the theory with additional random-effects panel regressions for each treatment where the Proposer's side-payment offer is the dependent variable and the independent variables are a constant and a period trend. We cluster standard errors by session, and Wald tests confirm that offers are greater than the predicted amount of 0 in both the Random and Earned treatments $(p<0.01)$.

Overall, these results are consistent with the findings of other studies on contests and conflict resolution (for a review see Dechenaux et al., 2012). Specifically, the findings that subjects sometimes use non-binding side-payment offers to successfully resolve conflicts (16\% in Random and $23 \%$ in Earned), replicate the findings of Kimbrough \& Sheremeta (2013), who report a conflict resolution rate of $14 \%$. The finding that subjects overinvest in conflict (modeled 
as a lottery contest) replicates the findings of a large experimental literature on rent-seeking (Davis \& Reilly, 1998; Potters et al., 1998; Anderson \& Stafford, 2003; Sheremeta, 2010a, 2010b, 2011; Sheremeta \& Zhang, 2010; Chowdhury et al., 2012; Mago, Samek \& Sheremeta, 2013; Mago, Sheremeta \& Yates, 2013).

These facts taken together indicate that our data replicate the patterns of deviation from the theory observed in other studies, so now we turn our focus to the hypothesized effects of earned rights.

\section{Earned rights}

First we examine whether the Earned treatment yields a significant increase in the probability of avoiding conflict. Recall, Hypothesis 1 states that earned rights should decrease entry by Responders and increase the probability of conflict resolution. Table 2 provides support for Hypothesis 1, indicating that conflict in the Earned treatment is resolved with significantly higher probability than in the Random treatment (probability of 0.23 versus 0.16 ), leading to $44 \%$ increase in the conflict resolution rate in the Earned case.

Finding 2: Earned rights increase the probability of conflict resolution because Proposers make persistent and significantly larger offers in the Earned treatment.

Table 3 displays the probability of conflict resolution by treatment, conditional on the size of the side-payment offer. For offers in the intervals $[0,15],(15,30]$, and $(30,60]$, the probability of avoiding conflict is increasing for both treatments, but the probability is consistently higher for the Earned treatment. This finding and a significant and negative effect of offer size on conflict probability are supported by regression analysis.

Specifically, as reported in Table 4, we estimate a linear probability model where the dependent variable Enter is one or zero indicating whether the Responder chose to enter the conflict stage. Restricting attention to non-zero offers, we estimate the impact of earned rights on the probability of entry, controlling for a period trend, the amount of offer, and whether the offer was accepted. We include random effects to account for multiple observations on each subject, and we cluster standard errors by session. The effect of earned rights (Earned) on the probability 
of conflict (Enter) is negative and weakly significant $(p=0.09)$, and the effect of offer size (Offer) is significant and negative $(p<0.01)$.

However, this regression underestimates the treatment effect because offers are persistently higher in the Earned treatment. The mean offer in the Earned treatment is 15.8 while it is only 12.3 in the Random treatment (Table 2). Figures $2 \mathrm{a}$ and $2 \mathrm{~b}$, displaying histograms of bargaining stage offers in the Random and Earned treatments, indicate the increase in the observed frequency of offers around 30 in the Earned treatment.

The effect of earned rights on offers is even more pronounced when we look at the change in the distribution of offers over time. Figure 3 displays time series of the mean offer in the Earned and Random treatments. In the first 10 periods, the mean offer of 18.7 in the Random treatment is marginally higher than the mean offer of 17.5 in the Earned treatment. However, by the final 10 periods, the mean offer in the Random treatment has fallen by $63 \%$ to 7.0 , while the mean offer in the Earned treatment has fallen only by $9 \%$ to 16.0 .

Regression analysis, reported in Table 5, indicates a significant relative decline in offers in the Random treatment. We estimate a panel regression with a random effects error structure to account for multiple observations on each subject, and we cluster standard errors at the session level. The dependent variable Offer is the amount of the side-payment offer, and the independent variables are a constant, a period trend Period, an Earned treatment dummy variable, and a term Period $\times$ Earned capturing the interaction of the period trend and the Earned rights dummy. The coefficient on the interaction term is positive and significant $(p<0.01)$ and the coefficient on period alone is negative and significant $(p<0.01)$. A Wald test cannot reject the linear hypothesis that the period trend Period and the Period $\times$ Earned interaction term sum to zero, which suggests that offers decline over time only in the Random treatment $(p=0.13)$.

To understand the source of the treatment effect on offers, Figure 4 displays time series of offers for each Proposer. In both the Random and Earned treatments, many subjects make substantial offers in early periods, but in the Earned treatment, far fewer of those subjects eventually reduce their offers to 0 . The bold outlined panels in Figure 4 show subjects who made cooperative offers in early periods and later reduced their offers. Eleven subjects in the Random treatment offered less than 5 (on average) over the final 10 periods, while only five subjects do the same in the Earned treatment. Hence, earned rights induce persistent attempts at cooperation, which translate into a $44 \%$ increase in the probability of conflict resolution. 
Despite the surplus gains from attempted cooperation and the resulting increase in the probability of avoiding conflicts, our data indicate that earned rights had no significant effect on total welfare ${ }^{11}$, in particular due to a reduction in Proposer payoffs (see Table 2). ${ }^{12}$ What explains these apparently contradictory tendencies? Table 6 displays statistics on offers, rejections, and conflicts in each treatment. To understand the source of the decrease in Proposers' payoffs, notice first that Proposers in the Earned treatment make non-zero offers $75 \%$ of the time versus only $70 \%$ in the Random treatment. Furthermore, Responders reject a slightly larger percentage of non-zero offers in the Random treatment, which allows Responders to retain more of the surplus. This partly explains the decrease in Proposers payoffs, but both effects are welfare neutral, given that side-payments merely transfer resources to the Responder. To understand why the Earned treatment does not generate an increase in total surplus, we analyze the conflict expenditures of each type in both treatments.

Finding 3: There is no significant effect of earned rights on total surplus because the increase in the rate of conflict resolution is offset by higher conflict expenditures by those Proposers who find themselves in a conflict after their offer is accepted.

According to Hypothesis 2, when conflict ensues, earned rights should increase contest expenditures by Proposers, thereby reducing surplus. Table 7 displays average conflict expenditure by treatment and subject type, depending on whether a positive offer was accepted or rejected. In the Random treatment, non-zero accepted offers lead Proposers to reduce their expenditures (either because the positive offer signals cooperative intentions or because they are cutting their losses), but in the Earned treatment, when Responders accept positive offers and still choose to enter the conflict, Proposers react spitefully, fighting just as hard as when their offers are rejected.

These results receive statistical support (see Table 8) in additional random-effects panel regressions, estimated separately for Proposers and Responders and restricted to observations in

\footnotetext{
${ }^{11}$ We estimate simple panel regressions, with subject-specific random effects and standard errors clustered by session where the dependent variable is surplus and the independent variables are a constant, a period trend, and an Earned treatment dummy. We cannot reject the null hypothesis that the Earned treatment has no effect $(p>0.7)$.

${ }^{12}$ We estimate additional random-effects panel regressions, with standard errors clustered by session, separately for Proposers and Responders. The dependent variable is individual payoff and the independent variables are a constant, a period trend, and an Earned treatment dummy. The effect of earned rights is negative and (weakly) significant only for Proposers in the Earned treatment $(p=0.06)$.
} 
which Proposers made non-zero offers. The dependent variable Expenditure is conflict expenditure and the independent variables are a constant, a period trend Period, the sidepayment Offer, an Earned treatment dummy, a binary variable Accept indicating whether the offer was accepted, and an interaction term Earned $\times$ Accept of the treatment dummy and whether the offer was accepted. We cluster standard errors by session. For Proposers, the coefficient on Accept is significant and negative $(p<0.02)$, which indicates that Proposers in the Random treatment invest less when their offers are accepted. On the other hand, the coefficient on the interaction term Earned $\times$ Accept is significant and positive $(p<0.02)$, and a Wald test cannot reject the hypothesis that the two coefficients sum to zero $(p=0.77)$. This indicates that in the Earned treatment Proposers fight by expending resources just as hard when their offer is accepted as when it is rejected, thus accounting for the diminished surplus. All other coefficients except the constant are insignificant $(p>0.5) .{ }^{13}$ In the estimated equation for Responders, all coefficients are insignificant $(p>0.15)$.

Finding 4: Controlling for offer size, Proposers in the Earned treatment expend more resources in conflict when their offers are accepted than Proposers in the Random treatment.

Taken together, this evidence explains why earned rights do not change the aggregate surplus, despite decreasing the probability of conflict. According to these findings, earned rights impact behavior in three important ways: (1) Proposers who have earned their position persistently offer larger side-payments; (2) larger offers lead to a lower probability of conflict; but (3) Earned Proposers whose offers do not lead to conflict resolution respond spitefully and spend just as much in conflict as when offers are rejected (Finding 3). Hence, with earned rights, the positive welfare effects of reduced conflict frequency are offset by greater conflict intensity, resulting in unchanged surplus.

\section{Discussion}

Our experiment generates three novel stylized facts that leave us with three motivational puzzles. First, we would like to be able to explain why earned rights induce Proposers to make

\footnotetext{
${ }^{13}$ An alternative specification excluding the interaction term shows no effect of accepting the offer and instead gives a positive and weakly significant coefficient on the Earned treatment dummy $(p=0.09)$, which imperfectly captures the same effect.
} 
persistent, out-of-equilibrium, large offers. Second, we want to understand why these offers are sometimes successful in eliminating conflict. Finally, we want to understand why conflict becomes more costly with earned entitlements.

In the end, though our experiment makes clear the behavioral impact of earned rights in a conflict setting, the underlying motivational impacts of earned rights are complex. We would argue that whether earned rights encourage cooperation or conflict depends on how they alter the beliefs of participants - if earned rights are salient and induce the belief that their holder has legitimately acquired a property right, then they may reduce the likelihood of conflict, as indeed we observe. But if only one party adopts this belief, then the ensuing conflicts may be more intense, as we also observe. In the study reported here, the positive and negative effects actually balance out one another, so that there is no change in total social welfare.

However, in our design, we do not directly observe or measure beliefs, so we cannot say with certainty that changes in beliefs are the source of observed changes in behavior. This is an important direction for future research. Perhaps an experiment that jointly elicits beliefs and actions in our setting would be able to identify the motivations of participants more directly. In particular such a design would be valuable for understanding the observed effect of earned rights on Proposer's offers. As we noted in the hypotheses section, this effect could have gone in either direction. If Proposers believed (a) that they had earned the prize and (b) that Responders believed (a), then we might have expected offers to decline. Those readers familiar with the ultimatum game literature may find this intuition appealing, as it is consistent with evidence there that earned rights increase the selfishness of Proposers. Instead, we observe persistent higher offers among these Proposers, suggesting perhaps that they were attempting to persuade Responders to adopt their beliefs. In this sense, offers can be viewed as a kind of "expensive talk" "14 meant to convey information about the Proposer's beliefs; indeed, why would a Proposer make a positive offer if he believed that no such offer could ever preclude conflict? When coupled with the fact that we observe higher conflict expenditures, conditional on entry, this interpretation seems plausible, as it seems that slighted Proposers react spitefully to entry by Responders. We hope that these issues will provide fruitful directions for future research.

\footnotetext{
${ }^{14}$ In contrast to "cheap talk".
} 


\section{Conclusion}

In many contexts, individuals and groups attempt to employ non-binding mechanisms to resolve costly conflicts. As our biblical example suggests, the threat of resource conflict has motivated attempts to implement such mechanisms, despite issues of enforceability, far into recorded history, and recent research suggests that similar mechanisms are at work in both small and large scales even today (e.g., Gurven, 2004; Kanbur, 2006; Schechter, 2007; Temple, 2010). However, the lack of naturally occurring data prevents us from answering exactly how nonbinding mechanisms resolve conflicts. Controlled laboratory experiments offer a useful methodology for studying conflict and conflict resolution (Arce et al., 2011; Imai et al., 2011; Dechenaux et al., 2012). Here, we use an experiment to explore how the effectiveness of nonbinding conflict resolution mechanisms depends on earned entitlements. In particular, we examine how earned rights to a valuable resource impact the following variables: (1) the willingness to offer payments intended to obviate resource conflict, (2) the willingness to accept such payments and voluntarily forgo conflict, and (3) the costs of conflicts that result from failed attempts at cooperation.

Previous literature documents that earned entitlements frequently increase the extent to which behavior approximates Nash play in bargaining games. When subjects observe that a decision maker has earned the right to an assigned role (e.g., the Proposer), the decision maker often behaves more selfishly and others are more likely to accept decisions that favor the rightholder (e.g., by accepting lower offers in ultimatum games, see Hoffman et al., 1994). However, in these papers, the disagreement payoff is exogenous and subjects whose offers are rejected have no opportunity to impact the payoffs of their counterpart after bargaining. Here we endogenize the disagreement payoff in the conflict stage, which allows us to identify both the gains from bargained conflict resolution and the costs of conflict escalation after bargaining fails.

We find that when Proposers earn the right to make side-payment offers, it creates a sense of entitlement to a share of the prize. Proposers respond by offering more and persisting in making high offers over time. These offers increase the rate of conflict resolution, but this does not improve welfare. When Proposers who earned their role observe their counterparts accepting transfer payments and nevertheless choosing to enter the conflict, they increase the intensity of conflict, offsetting the gains from higher conflict avoidance. 
Thus, while it would appear that there is some role for non-binding mechanisms to reduce the frequency of conflict, it is important to recognize that the effectiveness of such mechanisms is influenced in two countervailing ways by the presence of earned entitlements. In particular, our method of endogenizing the costs of conflict revealed a negative impact of entitlements that had not been measured in previous research. In any application, the relative magnitudes of the observed effects are likely to depend on both the perceived strength of the entitlements and the costs and benefits of conflict, and for all these reasons, we would urge caution in extrapolating from the success of earned entitlements in encouraging cooperation in previous work.

\section{Replication data}

All analyses were conducted using Stata 12 and R (R Core Team 2013). The dataset, replication Stata and $\mathrm{R}$ files and an output $\log$ for the empirical analysis can be found at http://www.prio.no/jpr/datasets.

\section{Acknowledgments}

We would like to thank the Associate Editor at the Journal of Peace Research and three anonymous referees for thoughtful and constructive comments. We also thank Bart Wilson for insightful comments and the Economic Science Institute at Chapman University for generous financial support. 


\section{References}

Alcock, John \& Winston J Bailey (1997) Success in territorial defence by male tarantula hawk wasps Hemipepsis ustulata: The role of residency. Ecological Entomology 22(4): 377383.

Anbarci, Nejat; Stergios Skaperdas \& Constantinos Syropoulos (2002) Comparing bargaining solutions in the shadow of conflict: How norms against threats can have real effects. Journal of Economic Theory 106(1): 1-16.

Arce, Daniel G; Rachel T Croson \& Catherine C Eckel (2011) Terrorism experiments. Journal of Peace Research 48(3): 373-382.

Butler, Christopher K \& Scott Gates (2012) African range wars: Climate, conflict and property rights. Journal of Peace Research 49(1): 23-34.

Cherry, Todd L; Peter Frykblom \& Jason F Shogren (2002) Hardnose the dictator. American Economic Review 92(4): 1218-1221.

Chowdhury, Subashish M; Roman M Sheremeta \& Theodore L Turocy (2012) Overbidding and overspreading in rent-seeking experiments: Cost structure and prize allocation rules. ESI Working Paper, Chapman University.

Davis, Douglas D \& Robert J Reilly (1998) Do too many cooks always spoil the stew? An experimental analysis of rent-seeking and the role of a strategic buyer. Public Choice 95(1-2): 89-115.

Dechenaux, Emmanuel; Dan Kovenock \& Roman M Sheremeta (2012) A survey of experimental research on contests, all-pay auctions and tournaments. ESI Working Paper, Chapman University (http://papers.ssrn.com/sol3/papers.cfm?abstract_id=2154022).

Deck, Cary \& Roman M Sheremeta (2012) Fight or flight? Defending against sequential attacks in the game of Siege. Journal of Conflict Resolution 56(6): 1069-1088.

DeScioli, Peter \& Bart J Wilson (2011) The territorial foundations of human property. Evolution and Human Behavior 32(5): 297-304.

Esteban, Joan M \& Josef Sakovics (2008) A theory of agreements in the shadow of conflict: The genesis of bargaining power. Theory and Decision 65(3): 227-252.

Gachter, Simon \& Arno Riedl (2005) Moral property rights in bargaining with infeasible claims. Management Science 51(2): 249-263.

Garfinkel, Michelle R \& Stergios Skaperdas (2000) Conflict without misperceptions or incomplete information: How the future matters. Journal of Conflict Resolution 44(5): 793-807.

Garfinkel, Michelle R \& Stergios Skaperdas (2007) Economics of conflict: An overview. In: Todd Sandler \& Keith Hartley (eds) Handbook of Defense Economics. New York: Elsevier, 649-710.

Garfinkel, Michelle R \& Stergios Skaperdas (2012) Oxford Handbook of the Economics of Peace and Conflict. New York: Oxford University Press.

Gintis, Herbert (2007) The evolution of private property. Journal of Economic Behavior and Organization 64(1): 1-16.

Grafen, Alan (1987) The logic of divisively asymmetric contests: Respect for ownership and the desperado effect. Animal Behaviour 35(2): 462-467.

Gurven, Michael (2004) To give or not to give: The behavioral ecology of human food transfers. Behavioral and Brain Sciences 27(4): 543-583.

Hafer, Catherine (2006) On the origins of property rights: Conflict and production in the state of nature. Review of Economic Studies 73(1): 119-143. 
Haley, Michael P (1994) Resource-holding power asymmetries, the prior residence effect and reproductive payoffs in male northern elephant seal fights. Behavioral Ecology and Sociobiology 34(6): 427-434.

Harris, Stephen L (1985) Understanding the Bible. Palo Alto: Mayfield.

Henrich, Joseph; Robert Boyd, Samuel Bowles, Colin Camerer, Ernst Fehr, Herbert Gintis \& Richard McElreath (2001) In search of homo economicus: Behavioral experiments in 15 small-scale societies. American Economic Review 91(2): 73-78.

Henrich, Joseph; Robert Boyd, Samuel Bowles, Colin Camerer, Ernst Fehr, Herbert Gintis, Richard McElreath, Michael Alvard, Abigail Barr, Jean Ensminger, Natalie Smith Henrich, Kim Hill, Francisco Gil-White, Michael Gurven, Frank W Marlowe, John Q Patton, \& David Tracer (2005) 'Economic man' in cross-cultural perspective: Behavioral experiments in 15 small-scale societies. Behavioral and Brain Sciences 28(6): 795-815.

Hoffman, Elizabeth \& Matthew Spitzer (1985) Entitlements, rights, and fairness: An experimental examination of subjects' concepts of distributive justice. Journal of Legal Studies 14(2): 254-297.

Hoffman, Elizabeth; Kevin McCabe, Keith Shachat \& Vernon L Smith (1994) Preferences, property rights, and anonymity in bargaining games. Games and Economic Behavior 7(3): 346-380.

Hoffman, Elizabeth; Kevin A McCabe \& Vernon L Smith (1998) Behavioral foundations of reciprocity: Experimental economics and evolutionary psychology. Economic Inquiry 36(3): 335-52.

Imai, Kosuke; Luke Keele, Dustin Tingley \& Teppei Yamamoto (2011) Unpacking the black box of causality: Learning about causal mechanisms from experimental and observational studies. American Political Science Review 105(4): 765-789.

Jones, NG Blurton (1984) A selfish origin for human food sharing: Tolerated theft. Ethology and Sociobiology 5(1): 1-3.

Kanbur, Ravi (2006) The economics of international aid. In: Serge-Christophe Kolm \& Jean Mercier Ythier (eds) Handbook of the Economics of Giving, Altruism and Reciprocity, Volume 2: Applications. Amsterdam: Elsevier, 1559-1588.

Kemp, Darrell J \& Christer Wiklund (2004) Residency effects in animal contests. Proceedings of the Royal Society of London B 271(1549): 1707-1711.

Kimbrough, Erik O \& Roman M Sheremeta (2013) Side-payments and the costs of conflict. International Journal of Industrial Organization 31(3): 278-286.

Konrad, Kai A (2009) Strategy and Dynamics in Contests. Oxford: Oxford University Press.

Linster, Bruce G; Richard L Fullerton, Michael Mckee \& Stephen Slate (2001) Rent-seeking models of international competition: An experimental investigation. Defence and Peace Economics 12(4): 285-302.

Mago, Shakun D; Anya Savikhin Samek \& Roman M Sheremeta (2013) Facing your opponents: Social identification and information feedback in contests. ESI Working Paper, Chapman University (http://papers.ssrn.com/sol3/papers.cfm?abstract_id=2080409).

Mago, Shakun D; Roman M Sheremeta \& Andrew Yates (2013) Best-of-three contest experiments: Strategic versus psychological momentum. International Journal of Industrial Organization 31(3): 287-296.

Maynard Smith, John (1982) Evolution and the Theory of Games. Cambridge: Cambridge University Press. 
Maynard Smith, John \& GA Parker (1976) The logic of asymmetric contests. Animal Behaviour 24(1): 159-175.

Muthoo, Abhinay (2004) A model of the origins of basic property rights. Games and Economic Behavior 49(2): 288-312.

Oxoby, Robert J \& John Spraggon (2008) Mine and yours: Property rights in dictator games. Journal of Economic Behavior \& Organization 65(3-4): 703-713.

Parker, GA (1974) Assessment strategy and the evolution of fighting behavior. Journal of Theoretical Biology 47(1): 223-243.

Potters, Jan C; Casper G de Vries \& Frans Van Linden (1998) An experimental examination of rational rent seeking. European Journal of Political Economy 14(4): 783-800.

R Core Team (2013) R: A language and environment for statistical computing. R Foundation for Statistical Computing, Vienna, Austria (http://www.R-project.org/).

Schechter, Laura (2007) Theft, gift-giving, and trustworthiness: Honesty is its own reward in rural Paraguay. American Economic Review 97(5): 1560-1582.

Sheremeta, Roman M (2010a) Expenditures and information disclosure in two-stage political contests. Journal of Conflict Resolution 54(5): 771-798.

Sheremeta, Roman M (2010b) Experimental comparison of multi-stage and one-stage contests. Games and Economic Behavior 68(2): 731-747.

Sheremeta, Roman M (2011) Contest design: An experimental investigation. Economic Inquiry 49(2): 573-590.

Sheremeta, Roman M \& JingJing Zhang (2010) Can groups solve the problem of over-bidding in contests? Social Choice and Welfare 35(2): 175-197.

Sugden, Robert (2005) The Economics of Rights, Cooperation and Welfare. New York: Palgrave Macmillan.

Temple, Jonathan RW (2010) Aid and conditionality. In: Dani Rodrik \& Mark Rosenzweig (eds) Handbook of Development Economics, Vol. 5. Amsterdam: Elsevier, 4415-4523.

Tingley, Dustin (2011) The dark side of the future: An experimental test of commitment problems in bargaining. International Studies Quarterly 55(2): 521-544.

Tingley, Dustin H \& Barbara F Walter (2011) Can cheap talk deter? An experimental analysis. Journal of Conflict Resolution 55(6): 996-1020.

Warington, George (1873) When Was the Pentateuch Written? New York: Pott, Young \& Co. Young, H Peyton (1993) The evolution of conventions. Econometrica 61(1): 57-84.

Erik O Kimbrough, b. 1984, $\mathrm{PhD}$ in Computational Sciences and Informatics (George Mason University, 2010); Assistant Professor of Economics (Maastricht University, 2010-2011); Assistant Professor of Economics (Simon Fraser University, 2011- ).

Roman M Sheremeta, b. 1982, PhD in Economics (Purdue University, 2009); Assistant Professor of Economics (Chapman University, 2009-2013); Associate Professor of Economics (Chapman University, 2013-2014); Assistant Professor of Economics (Case Western Reserve University, 2013- ). 
Table 1: Experimental design and theoretical predictions

\begin{tabular}{llcc}
\hline & & \multicolumn{2}{c}{ Treatment } \\
\cline { 3 - 4 } & Player & Random & Earned \\
\hline Side-payment offer, $s^{*}$ & Proposer & 0 & 0 \\
Probability of conflict resolution & Responder & 0.00 & 0.00 \\
\cline { 2 - 4 } Equilibrium expenditure, $e^{*}$ & Proposer & 15 & 15 \\
& Responder & 15 & 15 \\
\cline { 2 - 4 } Expected payoff, $E\left(\pi^{*}\right)$ & Proposer & 15 & 15 \\
Available surplus, $v$ & Responder & 15 & 15 \\
\cline { 2 - 4 } Equilibrium surplus, $\Pi^{*}$ & & 60 & 60 \\
\hline
\end{tabular}

Table 2: Average summary statistics by treatment

\begin{tabular}{llcc}
\hline \hline & & \multicolumn{2}{c}{ Treatment } \\
\cline { 2 - 4 } & Player & \multicolumn{1}{c}{ Random } & Earned \\
\hline Side-payment offer, $s$ & Proposer & $12.3(13.2)^{*}$ & $15.8(14.1)^{*}$ \\
Probability of conflict resolution & Responder & $0.16^{*}$ & $0.23^{*}$ \\
\cline { 2 - 4 } Average expenditure, $e$ & Proposer & $23.3(12.7)^{*}$ & $26.9(10.9)^{*}$ \\
& Responder & $23.9(12.8)^{*}$ & $27.3(12.3)^{*}$ \\
\cline { 2 - 4 } Average payoff, $\pi$ & Proposer & $5.1(33.1)^{*}$ & $1.9(34.1)^{*}$ \\
Total surplus, $\Pi$ & \multicolumn{2}{c}{$20.6^{*}$} & $16.5(29.2)$ \\
\cline { 2 - 4 } Standard deviations in parentheses. * Indicates that the data are statistically significantly \\
different from the equilibrium of the model with $p<0.01$ (Wald tests based on estimates \\
computed separately for each treatment and each variable of interest with subject- or pair- \\
specific random effects and standard errors clustered at the session level).
\end{tabular}


Table 3: Probability of conflict resolution conditional on the side-payment offer

\begin{tabular}{lcc}
\hline \multirow{2}{*}{ Offer } & \multicolumn{2}{c}{ Treatment } \\
\cline { 2 - 3 } & Random & Earned \\
\hline $0 \leq \mathrm{s} \leq 15$ & 0.09 & 0.06 \\
$15<\mathrm{s} \leq 30$ & 0.24 & 0.36 \\
$30<\mathrm{s} \leq 60$ & 0.48 & 0.64 \\
\hline
\end{tabular}

Table 4: Linear probability estimates of conflict entry, non-zero offers

\begin{tabular}{lc}
\hline \hline & Enter \\
\hline Offer & $-0.014^{*} *$ \\
Earned & $(0.003)$ \\
& $-0.052 \dagger$ \\
Accept & $(0.031)$ \\
& -0.012 \\
Period & $(0.092)$ \\
& $-0.003^{*}$ \\
Constant & $(0.001)$ \\
& $1.103^{*} *$ \\
& $(0.082)$ \\
\hline Observations & 781 \\
R Sq. & 0.169 \\
\hline Clustered standard errors in parentheses. \\
$\dagger p<0.10, * p<0.05, * * p<0.01$.
\end{tabular}


Table 5: Estimates of proposer's offers

\begin{tabular}{lc}
\hline \hline & Offer \\
\hline Period & $-0.495^{* *}$ \\
& $(0.089)$ \\
Earned & -2.589 \\
& $(4.065)$ \\
Period $\times$ Earned & $0.391 * *$ \\
& $(0.113)$ \\
Constant & $19.974^{* *}$ \\
& $(1.195)$ \\
\hline Observations & 1080 \\
R Sq. & 0.0664 \\
\hline Clustered standard errors in parentheses. \\
$\dagger p<0.10, * p<0.05, * * p<0.01$.
\end{tabular}

Table 6: Number of offers, rejections and conflicts

\begin{tabular}{lcc}
\hline \hline & \multicolumn{2}{c}{ Treatment } \\
\cline { 2 - 3 } & Random & Earned \\
\hline Total \# of offers & 540 & 540 \\
\# of non-zero offers & 377 & 404 \\
(Prob = non-zero/total) & $(0.70)$ & $(0.75)$ \\
\# of rejections & 199 & 169 \\
$\quad$ (Prob = rejections/total) & $(0.37)$ & $(0.31)$ \\
\# of non-zero rejections & 70 & 70 \\
$\quad$ Prob = rejections/non-zero) & $(0.19)$ & $(0.17)$ \\
\# of conflicts avoided & 89 & 125 \\
$\quad$ (Prob = avoided/total) & $(0.16)$ & $(0.23)$ \\
\hline Probabilities and conditional probabilities in parentheses.
\end{tabular}


Table 7: Mean non-zero offers and expenditures by treatment

\begin{tabular}{lllc|cc}
\hline \hline & & \multicolumn{3}{c}{ Treatment } \\
\cline { 3 - 6 } Decision & Player & Offer > 0 & Expenditure & Offer > 0 & Expenditure \\
\cline { 3 - 6 } Accept & Proposer & $16.9(12)$ & $20.9(12.4)$ & $20.9(11.4)$ & $28.2(11.6)$ \\
& Responder & $16.9(12)$ & $22.7(12.7)$ & $20.9(11.4)$ & $27.4(13.3)$ \\
\cline { 2 - 6 } Reject & Proposer & $9.6(9.7)$ & $26.8(11.4)$ & $8.9(8.5)$ & $27.8(9.9)$ \\
& Responder & $9.6(9.7)$ & $26.8(12.1)$ & $8.9(8.5)$ & $28.6(9.8)$ \\
\hline
\end{tabular}

Standard deviation in parentheses.

Table 8: Estimates of conflict expenditures by type

\begin{tabular}{lcc}
\hline \hline & \multicolumn{2}{c}{ Expenditure } \\
\cline { 2 - 3 } Offer & Proposer & Responder \\
Earned & -0.024 & 0.097 \\
& $(0.090)$ & $(0.080)$ \\
Period & 1.879 & 3.559 \\
& $(3.107)$ & $(3.120)$ \\
Accept & -0.078 & -0.024 \\
& $(0.155)$ & $(0.109)$ \\
Earned $\times$ Accept & $-3.812^{*}$ & -1.626 \\
& $(1.603)$ & $(1.144)$ \\
Constant & $(1.771)$ & -0.197 \\
& $27.118 * *$ & $24.339 * *$ \\
Observations & $(1.525)$ & $(2.515)$ \\
R Sq. & 588 & 588 \\
\hline Clustered standary & 0.0831 & 0.0397 \\
\hline
\end{tabular}

Clustered standard errors in parentheses.

$\dagger p<0.10, * p<0.05, * * p<0.01$. 

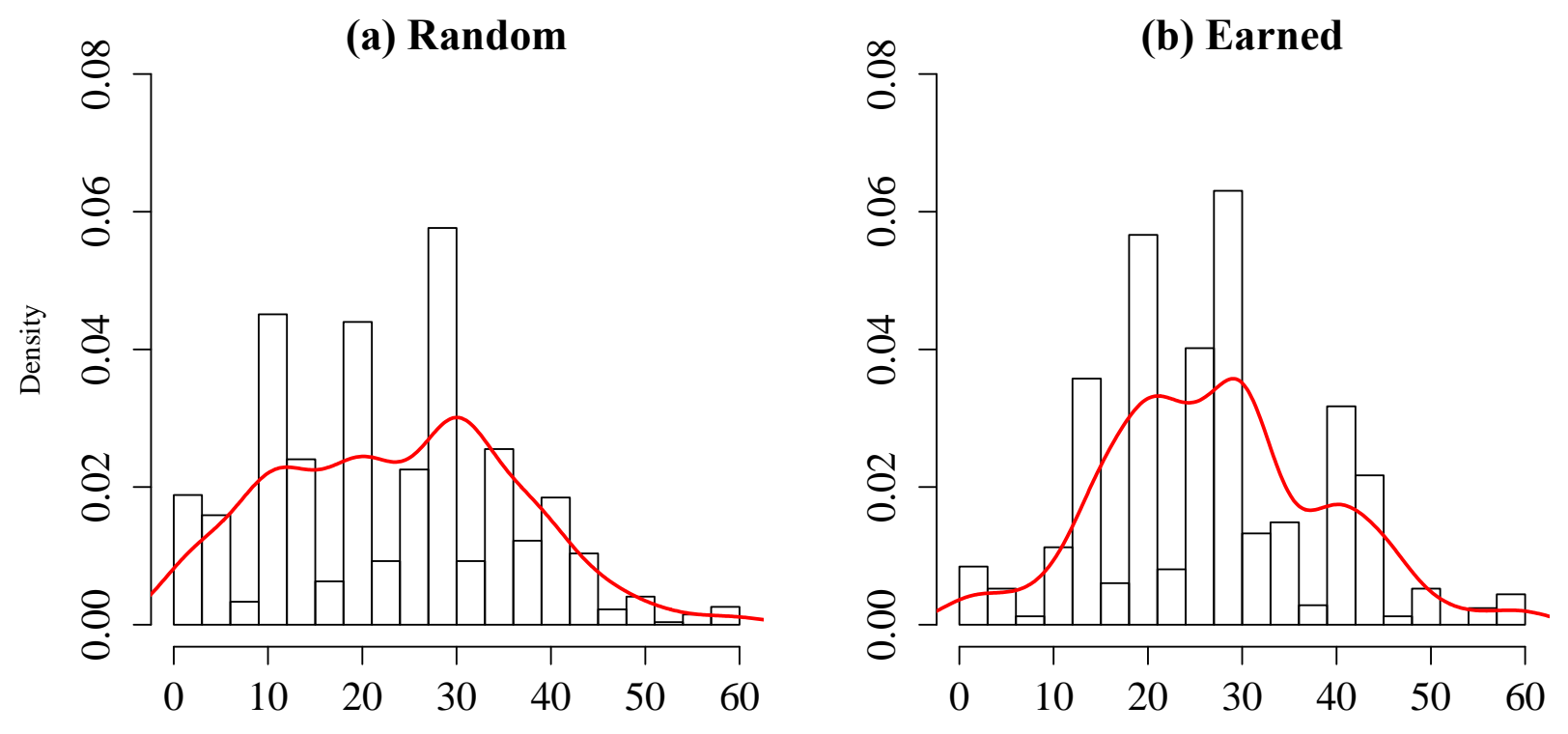

Figure 1: Histograms of conflict expenditures by treatment
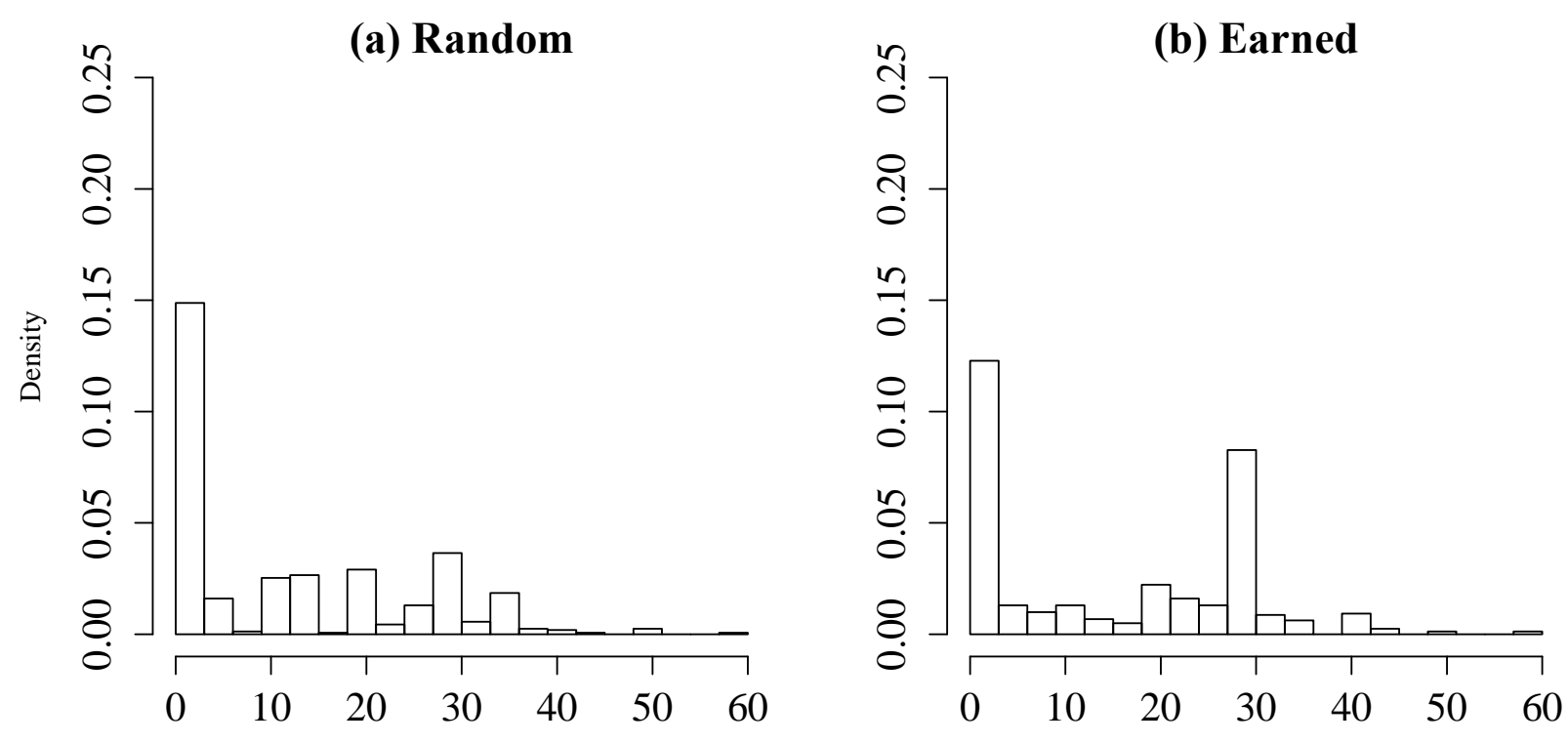

Figure 2: Histograms of bargaining offers by treatment 


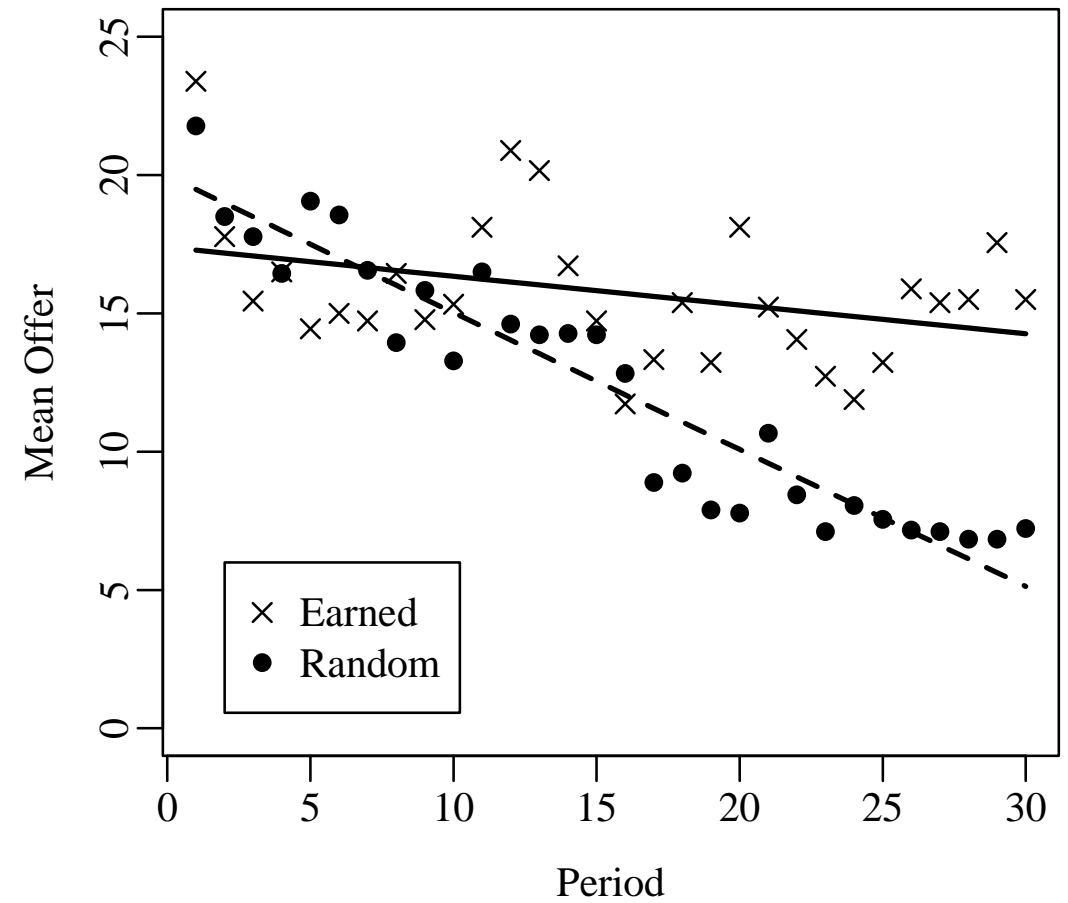

Figure 3: Time series of mean offers by treatment with OLS fit 


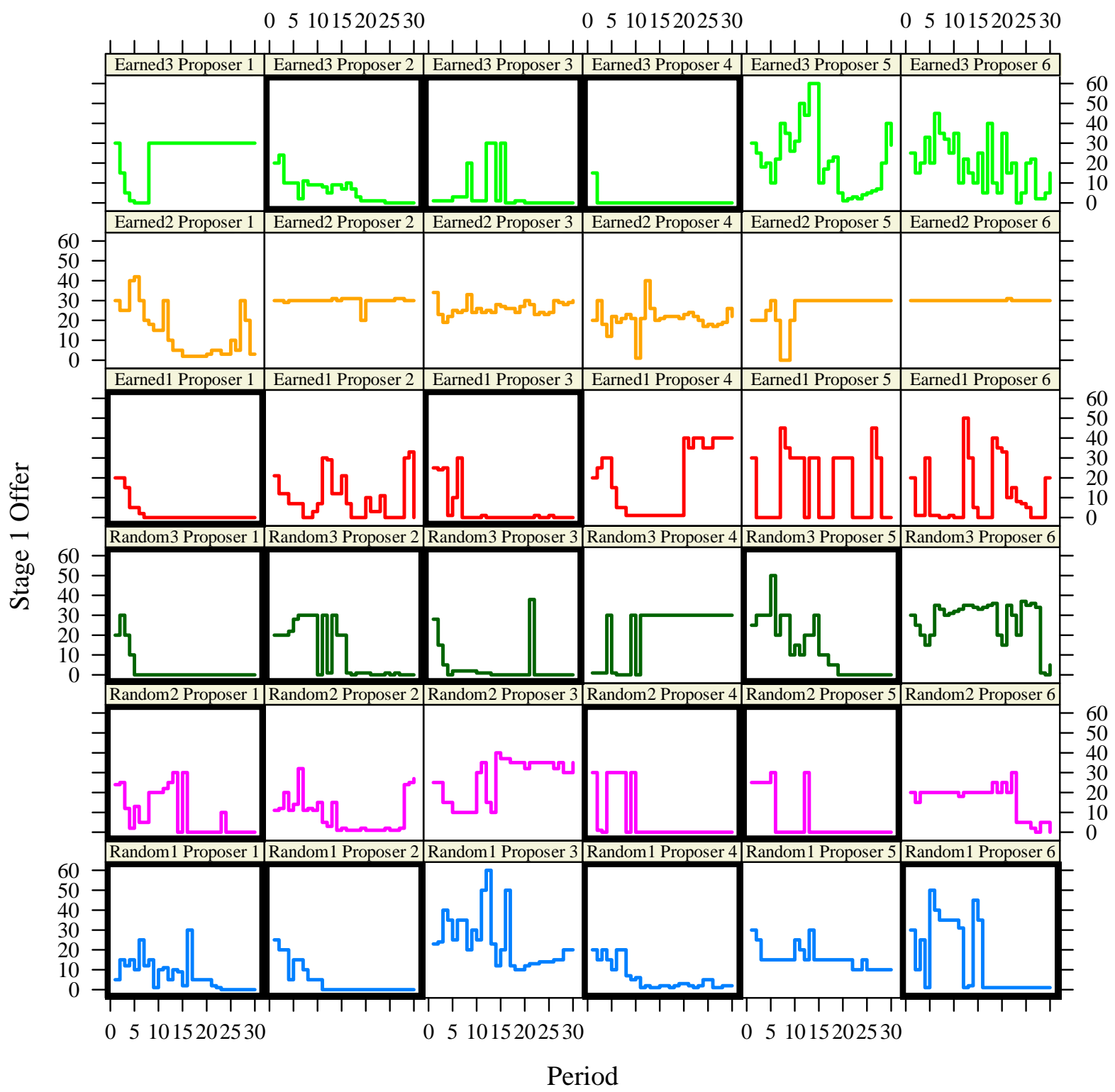

Note: Each row represents Proposers in 1 session (rows 1-3 Earned and rows 4-6 Random). Panels outlined in bold indicate subjects who offered less than 5 on average from period 21-30.

Figure 4: Step plots of proposer's offers by period and treatment 


\section{Appendix (for online publication only) - Instructions for the earned treatment}

\section{GENERAL INSTRUCTIONS}

This is an experiment in the economics of strategic decision-making. Various research agencies have provided funds for this research. The instructions are simple. If you follow them closely and make appropriate decisions, you and the 11 other participants in this experiment can earn an appreciable amount of money, which will be paid to you in CASH at the end of today's experiment.

The currency used in the experiment is francs. Francs will be converted to U.S. Dollars at a rate of 30 francs to $\_$_ dollar. You have already received a $\$ 20.00$ participation fee (this includes the $\$ 7$ show up fee). The experiment will consist of 30 periods and at the end of the experiment we will randomly choose 5 of the 30 periods for actual payment using a bingo cage. We will sum your total earnings for these 5 periods and convert them to a U.S. dollar payment.

It is very important that you remain silent and do not look at other people's decisions. If you have any questions, or need assistance of any kind, please raise your hand and an experimenter will come to you. If you talk, laugh, exclaim out loud, etc., you will be asked to leave and you will not be paid. We expect and appreciate your cooperation. The remainder of the instructions will describe the decisions you may face in each period.

\section{INSTRUCTIONS FOR STAGE 1}

At the beginning of each period, you will be randomly and anonymously placed into a group of 2 participants. Each randomly chosen pair will consist of one Proposer and one Responder.

The positions of Proposer and Responder will be determined by your scores on a quiz before the first period of the experiment. Each of you will be asked the same set of 10 questions. Your quiz score is the number of questions you answered correctly. Quiz scores will be ranked from highest to lowest and ties are decided by giving a higher ranking to the person who finishes the quiz in the shortest amount of time.

Once the complete rankings of participants are determined, you will enter your name, and the participants will be divided into two groups, the Proposers and the Responders. The lower ranking half will be Responders for all periods of the experiment. The higher-ranking half has earned the right to be Proposers. Your role will determine the decisions that you make.

Once the roles have been assigned, an experimenter will direct you to another computer. The computer will display in the middle of the screen which role you have been assigned.

The composition of your pair will be changed randomly every period. Each period will consist of two stages. In Stage 1, you and the other participant in your group will bargain over a reward. The reward is worth 60 francs to you and the other participant in your group.

\section{YOUR DECISION}

In each period, the Proposer will be endowed with the 60 franc reward and will have an opportunity to make an Offer to the Responder. The Proposer may offer any integer number of francs between 0 and 60 . An example of the Proposer's decision screen is shown below. 


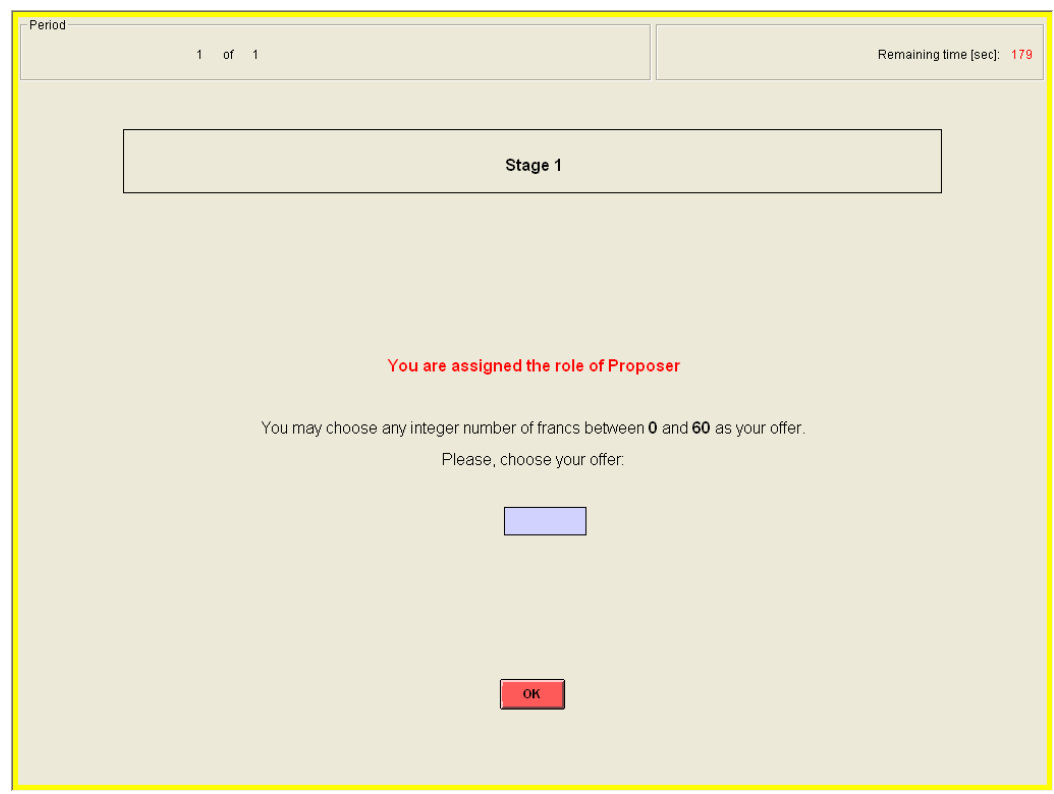

Once the Proposer has entered an offer and submitted that offer to the Responder, the Responder will choose either to Accept or Reject the offer and also whether to enter Stage 2 or not. An example of the Responder's decision screen is shown below.

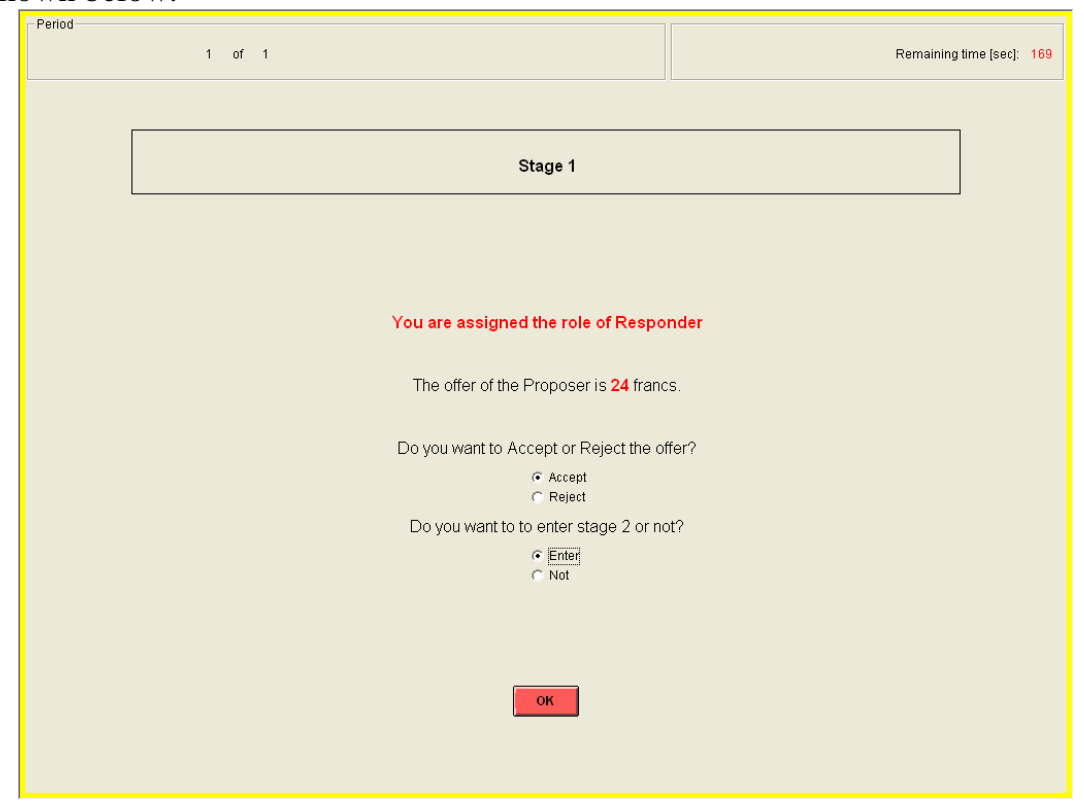

\section{EARNINGS}

If the Responder accepts the offer and decides not to enter stage 2, the Responder receives a payment equal to the offer, and the Proposer receives the 60 franc reward minus the amount of the offer:

$$
\begin{array}{ll}
\text { Proposer Earnings } & =60-\text { Offer } \\
\text { Responder Earnings } & =\text { Offer }
\end{array}
$$

If the Responder rejects the offer and decides not to enter stage 2, the Responder receives a payment equal to 0 , and the Proposer receives the 60 franc reward:

$$
\begin{array}{ll}
\text { Proposer Earnings } & =60 \\
\text { Responder Earnings } & =0
\end{array}
$$

If the Responder accepts the offer and decides to enter Stage 2, then the experiment moves to Stage 2 in which the Responder may attempt to take the reward. In that case, the Responder receives a payment equal to the earnings from Stage 2 plus the offer, and the Proposer receives the earnings from Stage 2 minus the offer: 


$$
\begin{array}{ll}
\text { Proposer Earnings } & =\text { Earnings in Stage } 2-\text { Offer } \\
\text { Responder Earnings } & =\text { Earnings in Stage } 2+\text { Offer }
\end{array}
$$

If the Responder rejects the offer, then the experiment moves to Stage 2 in which the Responder may attempt to take the reward. In that case, both participants will receive their earnings from decisions made in Stage 2:

$$
\begin{array}{ll}
\text { Proposer Earnings } & =\text { Earnings in Stage } 2 \\
\text { Responder Earnings } & =\text { Earnings in Stage } 2
\end{array}
$$

Note, if the Responder decides not to enter stage 2 (disregarding whether he accepts or rejects the offer) then the period ends after stage 1 . However, if the Responder decides to enter stage 2 (disregarding whether he accepts or rejects the offer) both participants will enter stage 2.

\section{INSTRUCTIONS FOR STAGE 2 \\ DECISION IN STAGE 2}

In Stage 2, the Responder may attempt to take the reward from the Proposer. Each participant may bid for the 60 franc reward. You may bid any integer number of francs between 0 and 60. An example of your decision screen is shown below.

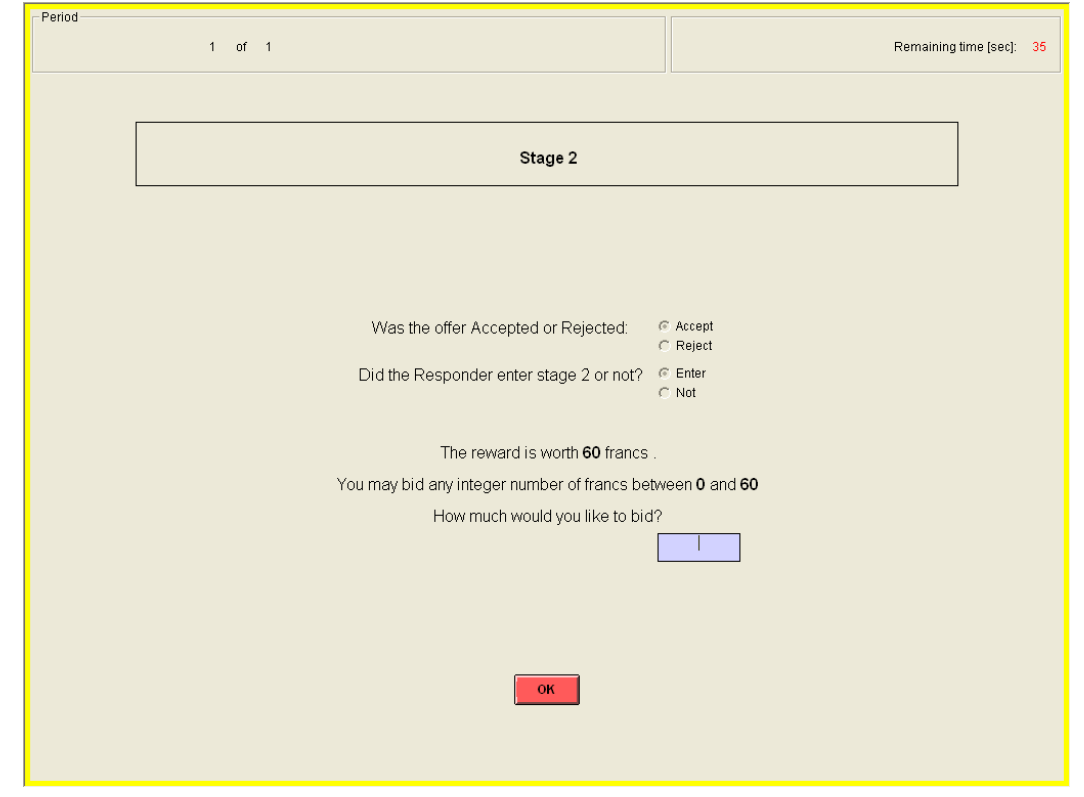

\section{EARNINGS IN STAGE 2}

After all participants have made their decisions, your earnings for the period are calculated. Regardless of who receives the reward, all participants will have to pay their bids. Thus, your earnings in stage 2 will be calculated in the following way:

If you receive the reward:

Earnings in Stage $2=60-$ Your Bid

If you do not receive the reward:

Earnings in Stage $2=0-$ Your Bid

Remember you have already received a $\$ 20.00$ participation fee (equivalent to 600 francs). Depending on a period, you may receive either positive or negative earnings. At the end of the experiment we will randomly select 5 out of 30 periods for actual payment. You will sum the total earnings for these 5 periods and convert them to a U.S. dollar payment. If the earnings are negative, we will subtract them from your participation fee. If the earnings are positive, we will add them to your participation fee.

\section{What Does my Bid Mean?}

The more you bid, the more likely you are to receive the reward. The more the other participant in your group bids, the less likely you are to receive the reward. Specifically, for each franc you bid you will receive one lottery ticket. At the end of each period the computer draws randomly one ticket among all the tickets purchased by you and the other participant in the group. The owner of the drawn ticket receives the reward worth 60 francs. Thus, 
your chance of receiving the reward is given by the number of francs you bid divided by the total number of francs you and the other participant in your group bids.

$\operatorname{Pr}($ Winning $)=\frac{\text { Your Bid }}{\text { Your Bid }+ \text { Other Participant's Bid }}$

If both participants bid zero, the reward is randomly assigned to one of the two participants in the group.

\section{Example of the Random Draw}

This is a hypothetical example used to illustrate how the computer is making a random draw. If participant 1 bids 10 francs and participant 2 bids 20 francs, the computer assigns 10 lottery tickets to participant 1 and 20 lottery tickets to participant 2 . Then the computer randomly draws one lottery ticket out of $30(10+20)$. As you can see, participant 2 has higher chance of receiving the reward: $0.67=20 / 30$. Participant 2 has $0.33=10 / 30$ chance of receiving the reward.

After all participants make their bids, the computer will make a random draw which will decide who receives the reward. Then the computer will calculate your period earnings based on your bid and whether you received the reward or not.

At the end of each period, the Proposer's offer, whether the offer was accepted, whether the Responder entered Stage 2, your bid, the other participant's, whether you received the reward or not, and the earnings for the period are reported on the outcome screen as shown below. Once the outcome screen is displayed you should record your results for the period on your Personal Record Sheet under the appropriate heading. An example of the outcome screen is shown below.

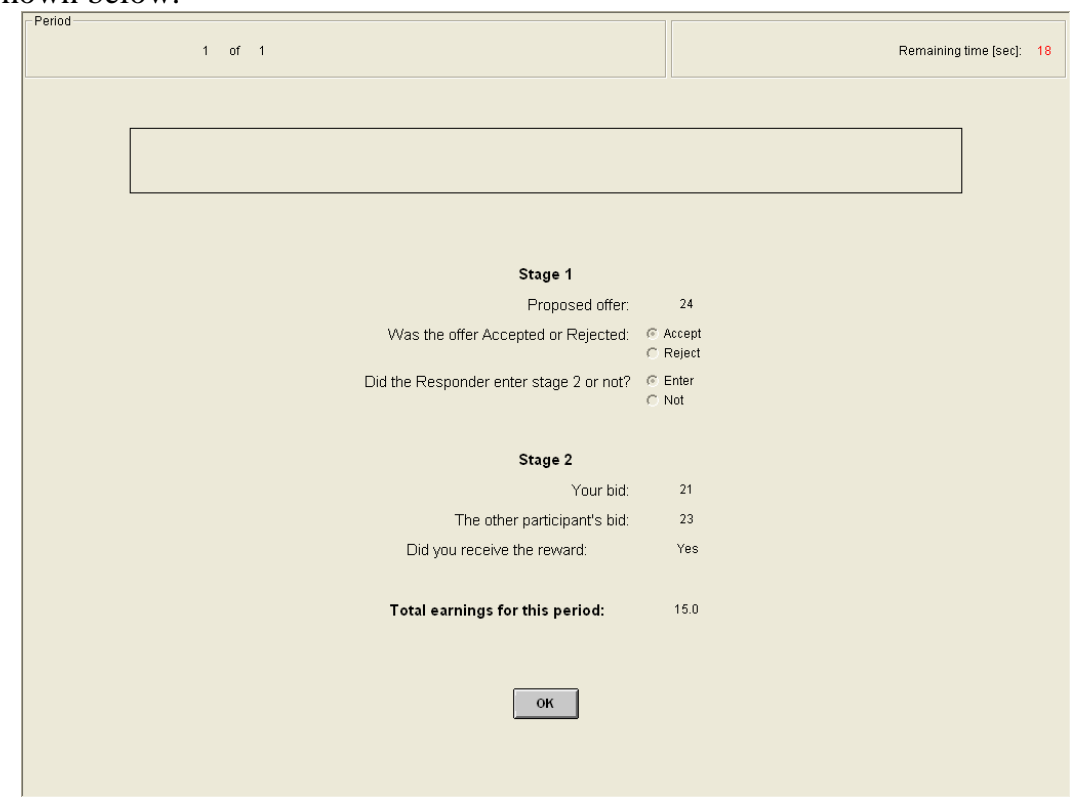

\section{IMPORTANT NOTES}

You will not be told which of the participants in this room are assigned to which group. At the beginning of each period you will be randomly re-grouped with one other participant to form a two-person group. You can never guarantee yourself the reward. However, if you are the Proposer in stage 1, and the Responder decides not to enter stage 2, you will receive the reward. Furthermore, if the experiment proceeds to stage 2 then by increasing your bid in stage 2, you can increase your chance of receiving the reward. In stage 2, regardless of which participant receives the reward, all participants must pay their bids.

Are there any questions? 